\title{
Valorização dos profissionais da educação Desafios para garantir conquistas da democracia ${ }^{1}$
}

\author{
Luiz Fernandes Dourado*
}

\begin{abstract}
RESUMO: $\mathrm{O}$ artigo tem por eixo as conferências nacionais, o PNE e as proposições de pareceres $\mathrm{CNE} / \mathrm{CP}$ de minha autoria, aprovados por unanimidade pelo Conselho Nacional de Educação e homologados pelo MEC, resultando em resoluções, como as Diretrizes Curriculares Nacionais para a Formação Inicial e Continuada de Profissionais do Magistério e as Diretrizes Curriculares Nacionais para a Formação Inicial e Continuada de Funcionários da Educação, e no Decreto que instituiu a Política Nacional de Formação dos Profissionais da Educação Básica, hoje ameaçadas, a despeito do que se conquistou nos últimos anos.
\end{abstract}

Palavras-chave: Políticas educacionais. PNE. Valorização. Formação. Profissionais da educação.

\section{Introdução}

$\mathrm{E}$ ste artigo, sem prescindir de uma concepção ampla de valorização, busca situar e contextualizar as novas DCN e a política nacional de formação, com o objetivo de discutir estes novos marcos e delinear caminhos e possibilidades para sua materialização, no âmbito do diversificado e diferenciado sistema de educação superior brasileiro. Ressalta-se, ainda, os limites que advêm do novo cenário político em que se apresenta o País, marcado por retrocessos na ordem democrática e por políticas de ajustes estruturais que afetam os diferentes setores, sobretudo as políticas sociais. Tal

* Doutor em Educação e pós-doutorado na École des hautes études en sciences sociales (EHESS) - Paris/FR. Professor Emérito e Titular da Universidade Federal de Goiás (UFG), membro do Conselho Superior e do Conselho Técnico Científico da Educação Básica da Coordenação de Aperfeiçoamento de Pessoal de Nível Superior (CTC/Capes), membro do Conselho Editorial da revita Retratos da Escola e pesquisador do CNPq. Ex-membro da Câmara de Educação Superior do Conselho Nacional de Educação (CES/CNE) 2012/2016. Goiânia/GO - Brasil. E-mail:<luizdourado2@gmail.com>. 
cenário requer vigor no combate aos retrocessos que demarcam as políticas atuais, bem como a luta pela efetiva materialização do Plano Nacional de Educação e das políticas educacionais que lhe são decorrentes, em direção à educação pública, laica, gratuita, democrática e de qualidade para todos/as e, no bojo destas, para políticas de valorização dos profissionais da educação.

\title{
Trajetória e concepções em disputa
}

A valorização dos profissionais da educação tem sido objeto de vários olhares, proposições e lutas políticas permeado por concepções distintas sobre valorização, bem como sobre quem são os profissionais da educação

A Conferência Nacional de Educação (CONAE/2014) apresenta uma concepção ampla sobre valorização do profissional da educação. Rompendo com a visão de valorização restrita ou tributária da formação, o documento final da Conae define que a valorização dos profissionais da educação envolve, de maneira articulada, a formação inicial e continuada, carreira, salários e condições de trabalho.

Essa concepção é fundamental para que avanços se materializem na valorização dos profissionais da educação.

As deliberações da Conae se articulam a movimentos em prol dessa valorização, envolvendo embates na tramitação e aprovação do PNE, políticas e diretrizes nacionais visando superar um cenário marcado pela necessidade de diretrizes nacionais para as carreiras, piso salarial nacional para todos, melhoria das condições de trabalho e garantia de formação inicial e continuada para os profissionais da educação.

Merece ser ressaltado, ainda, a relação entre profissão, profissionalização e profissionalidade, que se articula a esse debate, cujo critério é o caráter de política pública e a vinculação com a valorização do/a profissional, e que foi sintetizado por Vieira (2009, p. 327-328) ao afirmar que profissão refere-se à

\begin{abstract}
[...] a atividade exercida no mundo do trabalho e reconhecida institucionalmente. $\mathrm{O}$ profissional da educação se ocupa da educação escolarizada e preenche os requisitos de formação e dedicação à tarefa educativa sistematizada. No serviço público, o pré-requisito para o ingresso na profissão é a aprovação em concurso público. A profissionalização resulta de um conjunto de condições indissociáveis: salário, carreira, formação e condições de trabalho. Profissionalização significa superação da ideia de "missão", de continuidade das atribuições da família, como no conceito de "tia", contestado por Paulo Freire. Significa, também, o contraponto ao "apoliticismo", à construção cultural de que o educador tem compromisso com os eventuais mandatários, não com o Estado e a sociedade, e, portanto, não pode contrariar os detentores do poder.
\end{abstract}

Outro conceito que identifica o profissional de educação é o de profissionalidade. Ele expressa, objetiva e/ou subjetivamente, o compromisso com a educação e, também,com o 
projeto de sociedadeNão se limita às condições objetivas de trabalho,mas vincula-se à construção da identidade profissional, na sua dimensão intelectual, ética, política e cultural.

Essas concepções são fundamentais para discutir e avançar a agenda ampla que compõe a valorização envolvendo questões como formação inicial e continuada, carreira, salários e remunerações, condições de trabalho e saúde, que certamente interferem no pensar e no fazer político-pedagógico do profissional da educaçãoo e, portanto, na sua profissão, profissionalização e profissionalidade.

Historicamente, os profissionais do magistério da educação básica se constituíram como categoria profissional a partir da caracterização identitária como profissionais da educação.

Muitos debates e concepções em disputa marcam a trajetória desses profissionais envolvendo questões como formação e atuação profissional, entre outros. Trata-se de categoria expressiva, constituída por mais de dois milhões de profissionais, que atuam nas etapas e modalidades educativas da educação básica.

A despeito da consolidação identitária do profissional do magistério, a categoria apresenta inúmeros desafios, que envolvem salários, condições de trabalho, formação, entre outros. Para ilustrar esse cenário, os indicadores a seguir são relevantes à medida que sinalizam o grande desafio de garantir a formação, em nível superior, para mais de $25 \%$ do total de 2.141.676 de docentes (desse total 0,3\% não possuem o ensino médio). Outra questão a ser objeto de diagnostico, visando o estabelecimento de planejamento e políticas para a formação, diz respeito aos professores com licenciatura em uma determinada disciplina ou área e atuam em área distinta, muitas das vezes para complementar a carga horária.

\section{Tabela 1 - Número de Docentes Atuando na Educação Básica e Proporção por Grau de Formação - Brasil - 2007-2013}

\begin{tabular}{|c|c|c|c|c|c|c|c|c|}
\hline \multirow[b]{3}{*}{ Ano } & \multirow{3}{*}{$\begin{array}{c}\text { Número } \\
\text { de } \\
\text { docentes }\end{array}$} & \multicolumn{7}{|c|}{ Proporção de docentes por grau de formação } \\
\hline & & \multicolumn{2}{|c|}{ Ensino Fundamental } & \multicolumn{4}{|c|}{ Ensino Médio } & \multirow[b]{2}{*}{$\begin{array}{l}\text { Educação } \\
\text { Superior }\end{array}$} \\
\hline & & Incompleto & Completo & Total & $\begin{array}{l}\text { Normal/ } \\
\text { Magistério }\end{array}$ & $\begin{array}{c}\text { Sem } \\
\text { Normal/ } \\
\text { Magistério }\end{array}$ & $\begin{array}{l}\text { Superior } \\
\text { em } \\
\text { Andamento }\end{array}$ & \\
\hline 2007 & $1.878,284$ & 0,2 & 0,6 & 30,8 & 25,3 & 5,5 & $\ldots$ & 68,4 \\
\hline 2008 & $1.983,130$ & 0,2 & 0,5 & 32,3 & 25,7 & 6,5 & $\ldots$ & 67,0 \\
\hline 2009 & 1.972 .333 & 0,2 & 0,5 & 31,6 & 24,5 & 7,1 & $\ldots$ & 67,7 \\
\hline 2010 & $1.999,518$ & 0,2 & 0,4 & 30,5 & 22,5 & 8,0 & $\ldots$ & 68,8 \\
\hline 2011 & $2.039,261$ & 0,2 & 0,4 & 28,7 & 19,0 & 6,4 & 3,3 & 70,7 \\
\hline 2012 & $2.095,013$ & 0,1 & 0,3 & 26,5 & 16,0 & 5,5 & 5,0 & 73,1 \\
\hline 2013 & $2.141,676$ & 0,1 & 0,2 & 24,9 & 13,9 & 4,9 & 6,1 & 74,8 \\
\hline
\end{tabular}

Fonte: MEC/Inep/Deed.

Nota: 1) O docente foi computado apenas uma vez, mesmo atuando em mais de uma etapa/modalidade.

2) Não inclui auxiliares da educação infantil.

3) Não inclui os professores de turmas de atividade complementar e de Atendimento Educacional Especializado (AEE). 
É preciso considerar, ainda, a necessidade de contratação de novos profissionais do magistério para atender a expansão, projetada para 2016, de universalização da educação básica obrigatória (4 a 17 anos). Outro indicador relevante refere-se ao contingente de profissionais em idade para aposentadoria, cuja substituição vai requerer novas contratações.

Os funcionários da educação básica, categoria que conta com mais de um milhão de profissiona², tem trajetória histórica marcada pela "secundarização", "invisibilidade"e, só mais recentemente, por meio de muitas lutas vem sendo reconhecido.

A esse respeito é importante e emblemática a afirmação de Monlevade (2009, p.341) ao afirmar que

Pouquíssimo se tem pesquisado acerca do pessoal que compunha "o corpo de educadores" [...] A visão reducionista dos estudiosos da educação escolar, que só conseguem perceber em cena, nas escolas, professores e alunos, torna os demais "invisíveis". A realidade, entretanto, é que sempre estiveram presentes nas escolas outros trabalhadores.

Ao situar historicamente a trajetória dos funcionários da educação básica, o autor traz os elementos para responder à indagação de um de seus livros Funcionários de Escolas Públicas: Educadores Profissionais ou Servidores Descartáveis?. Importante salientar que é na luta que essa categoria vai saindo da "invisibilidade" e construindo a sua identidade como profissional da educação. A esse respeito, Monlevade (2009, p. 346) afirma que

Os funcionários de escola, vítimas de maior opressão, começaram a se "abrigar" em associações de professores, algumas com novas denominações como a União dos Trabalhadores em Educação de Minas Gerais, Associação mato-grossense de Profissionais da Educação, para ficar em dois exemplos. Ou partiram para fundar organizações próprias _ o que aconteceu em São Paulo (Afuse), no Paraná e no Distrito Federal (SAE).

Esses processos de afirmação identitária resultaram de múltiplos movimentos e lutas com especial realce para o papel dos sindicatos e do Governo Federal, a partir de 2003, que desencadeou ações e políticas direcionadas à valorização dos profissionais.

Ainda merecem realce as lutas em prol da unificação dos trabalhadores em educação, por meio da criação da Confederação Nacional dos Trabalhadores em Educação (CNTE). Esse processo impulsionou o movimento em prol da identidade dos profissionais da educação, envolvendo docentes e funcionários, contribuindo para o fortalecimento de suas lutas e bandeiras históricas.

A respeito do papel da CNTE no processo histórico de lutas pela organização, construção e afirmação da identidade e valorização desses profissionais, Fernandes (2009, p. 315) afirma que

A CNTE tem um papel fundamental nessa nova definição. E o processo tem uma origem mais orgânica, quando os professores constituíram suas entidades, chamadas associações, começam a fazer a luta sindical e consequentemente envolviam 
os outros trabalhadores, ou filiando-se a entidade ou unificando todos nas lutas da categoria. Claro que os funcionários da escola também começaram a reinvidicar espaço, tanto nessas organizações, quanto nas mobilizações. Sugiram, em alguns casos, entidades unificadas (Sind-UTE/MG) ou entidades específicas de funcionários (Afuse/SP). Mas o grande momento de definição orgânica foi quando os traalhadores em educação decidiram a unificação nacional, entre 1990 e 1991, ou seja, a decisão de criar e construir a CNTE. Essa decisão também ajudou a unificação em vários estados.

\section{Situando a importância da unificação Fernandes (2009, p.315) afirma que}

[...] a discussão da unificação mudou a composição das nossas entidades estaduais e nacional, e ajudou a melhorar as relações nos locais de trabalho, ou seja, fez com que se entendesse que tínhamos outros trabalhadores dentro da escola. Aliás, em alguns casos fez com que o cartaz convocando a assembleia, agora unificada, fosse colocado não apenas na sala dos professores, mas num local mais visível para todos.

Na CNTE, a criação do Departamento de Funcionários da Escola como iniciativa fundamental para a consolidação desse segmento como profissional da educação. Nessa Direção, Leão (2009, p. 315) afirma que

A CNTE surge do processo de unificação das lutas dos trabalhadores em educação (professores, funcionários, supervisores, orientadores, diretores de escola etc), entendendo que todos fazem parte de um grande ramo de trabalhadores. A partir do momento em que deixa de ser Confederação dos Professores do Brasil (CPB), passa a trabalhar na unidade de todo ramo. No Departamento de Funcionários de Escola (Defe), que neste ano completa 15 anos [2009], organizamos os trabalhadores para que eles se entendam como profissionais da educaçãoo, tratamos suas reivindicações específicas como do conjunto da CNTE. Por exemplo, hoje discutimos no Conselho Nacional de Educação diretrizes para a carreira dos funcionários de escola, o que inclui propostas de formação em serviço, participaçãoo na construção do projeto polític-pedagógico da escola etc., pois eles são parte integrante do processo educativo.[...]

\section{A respeito das conquistas dos funcionários, Cleide (2009, p.317) afirma que}

A participação de funcionários de escolas no movimento sindical foi fundamental para que fossem reconhecidos como protagonistas. $\mathrm{O}$ fato marcante para $a=$ organização sindical foi a criação do Defe. Tenho a honra de ter participado ativamentedessa luta e de uma de suas principais conquistas - a Lei no 12.014 , de 2009 que alterou o art. 61 da LDB, reconhecendo os funcionários de escola como profissionais de educação.

Após muitas lutas e proposições, os funcionários da educação básica passam a ser considerados profissionais da educação a partir de alterações na Lei de Diretrizes e Bases da educação nacional que definiu no artigo 61 da LDB, por meio de alterações ocorridas após a sua aprovação, os seguintes termos: (Redação dada pela Lei nº 12.014, de 2009) 
Art. 61. Consideram-se profissionais da educação escolar básica os que, nela estando em efetivo exercício e tendo sido formados em cursos reconhecidos, são:

I - professores habilitados em nível médio ou superior para a docência na educação infantil e nos ensinos fundamental e médio;

II - trabalhadores em educação portadores de diploma de pedagogia, com habilitação em administração, planejamento, supervisão, inspeção e orientação educacional, bem como com títulos de mestrado ou doutorado nas mesmas áreas;

III - trabalhadores em educação, portadores de diploma de curso técnico ou superior em área pedagógica ou afim. (Incluído pela Lei nº 12.014, de 2009) (BRASIL, 2009).

Por essa definição são profissionais da educação os professores e os trabalhadores da educação com formação técnica ou superior em área pedagógica ou afim. Essa mudança na LDB recontextualiza o que se entende por educação e redefine os diferentes profissionais que a constroem no cotidiano das instituições de educação básica.

A despeito desses avanços, as condições dos funcionários da educação básica são as mais diversas e fortemente marcadas por assimetrias. Em alguns casos, gozam de plano de carreira e, em outros, os sistemas tem optado pela terceirização ou outras formas precárias de contratação.

A construção da identidade dos profissionais da educação tem sido resultante de discussões, embates e proposições diversas como demonstramos ${ }^{3}$. Nas últimas décadas, outros importantes avanços se efetivaram na agenda da legislação e das políticas nacionais, destacando, entre outros: a Lei no 11.738, de 2008, que instituiu o Piso Salarial Profissional Nacional para os Profissionais do Magistério Público da Educação Básica; a Lei no 12.014, de 2009, que definiu, na Lei de Diretrizes e Bases da Educação Nacional (LDB), as categorias de trabalhadores considerados profissionais da educação; a Resolução CNE/CEB n⿳亠 2, de 2009 do Conselho Nacional de Educação, que fixou as Diretrizes Nacionais para os Planos de Carreira e Remuneração dos Profissionais do Magistério da Educação Básica Pública, em conformidade com a Lei nํ⒒738, de 2008; a Resolução no 5, de 2005 do Conselho Nacional de Educação que instituiu a área de Serviços de

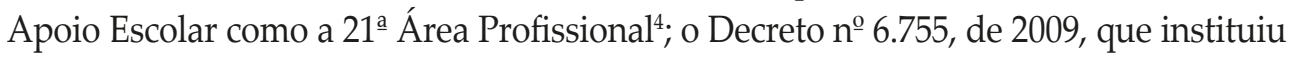
a Política Nacional de Formação de Profissionais do Magistério da Educação Básica; o Decreto nำ 7.415, de 30 de dezembro de 2010 que instituiu a Política Nacional de Formação dos Profissionais da Educação Básica, dispõe sobre o Programa de Formação Inicial em Serviço dos Profissionais da Educação Básica dos Sistemas de Ensino Público (Profuncionário), e dá outras providências (entre outros).

Todos esses dispositivos legais sinalizam avanços para os profissionais da educação. O esforço efetivado pelo MEC para a formação em nível médio dos funcionários da educação básica, por meio do Profuncionários ${ }^{5}$, a partir das seguintes áreas: gestão escolar, alimentação escolar, multimeios didáticos e meio ambiente e manutenção da 
infraestrutura escolar. A formação inicial em nível médio estimulou a luta em prol da formação superior como elemento importante a consolidação da identidade desses profissionais.Portanto, são enormes os desafios para pensar a valorização dos profissionais da educação, a despeito do que se conquistou nos últimos anos.

\section{O PNE e as Políticas e Diretrizes Nacionais para a Formação}

A aprovação do Plano Nacional de Educação (PNE) pelo Congresso Nacional e a sanção Presidencial, sem vetos, que resultaram na Lei nํ⒔005, de 2014, em consonância com o artigo 214 da Constitução Federal (BRASIL, 1988), situam o plano como epicentro das políticas educacionais brasileiras. Por essa razão, é fundamental lutar para que ele se materialize, visando garantir maior organicidade para a educação nacional no decênio 2014/2024, por meio de suas diretrizes, 20 metas e várias estratégias, que englobam a educação básica e a educação superior, em suas etapas e modalidades, bem como questões atinentes à base nacional comum, qualidade, avaliação, gestão, financiamento educacional e valorização dos profissionais da educação.

Tendo por eixo o Plano Nacional de Educação, com especial destaque para as suas diretrizes, metas e estratégias, é possível afirmar que a valorização dos profissionais da educação ganhou espaço no PNE, sobretudo nas metas 15,16, 17 e 18.

Ao analisar o PNE, Dourado (2016) destaca sua importância, a despeito dos limites, e no tocante à valorização profissional analisa as metas 15 a 18, sinalizando sobre sua materialização. A esse respeito afirma

A Meta 15, garantir, em regime de colaboração entre a União, os estados, o DF e os municípios, no prazo de um ano de vigência deste PNE, política nacional de formação dos profissionais da educação, tem sido objeto de luta e reivindicação pelos segmentos acadêmicos e sindicais e se articula às deliberações da Conae.

Destaquem-se dois movimentos para a efetivação dessa meta e de boa parte de suas estratégicas: 1) a aprovação do Parecer CNE/CP n² 2, de 2015, em 9 de junho de 2015, cuja homologação pelo MEC efetivou-se em 25 de junho de 2015 e, em decorrência desse parecer, a Resolução CNE/CP no 2, de 2015, de 1 de julho de $2015 ; 2)$ a proposta de política nacional de formação de profissionais da educação, lançada pelo MEC, em 25 de junho de 2015, e submetida a consulta pública, que ratifica as concepções contidas no Decreto n⿳ำ 6.755, de 29 de janeiro de 2009, sobre a Política Nacional de Formação de Profissionais do Magistério da Educação Básica, e insere questões específicas da formação dos funcionários e técnicos, visando a conferir maior organicidade à formação dos profissionais da educação.

Um dos pontos questionados pelas entidades do campo que será objeto de luta na proposição e materialização desta política se vincula à alteração de seu escopo institucional, incluindo o setor público e todo o setor privado. Tal proposição, adotada na proposta do MEC, se articula à estratégia 15.2, que visa a consolidar o financiamento estudantil a estudantes de cursos de licenciatura com avaliação positiva pelo Sistema Nacional de Avaliação da Educação Superior (Sinaes), 
inclusive a amortizar o saldo devedor pela docência efetiva na rede pública de educação básica.

A Meta 16, formar, em nível de pós-graduação, 50\% dos professores da educação básica até o último ano de vigência deste PNE e garantir a todos/as os/ as profissionais da educação básica formação continuada em sua área de atuação, considerando as necessidades, demandas e contextualizações dos sistemas de ensino, articula-se à meta anterior e apresenta importantes estratégias. Por outro lado, é importante destacar a previsão de bolsas de estudo (estratégia 16.5) para pós-graduação dos/as professores/as e demais profissionais da educação básica sem explicitar a natureza dessas bolsas, o que poderá ensejar demandas as mais diversas.

A Meta 17 consiste em valorizar os/as profissionais do magistério das redes públicas de educação básica de forma a equiparar seu rendimento médio ao dos/ as demais profissionais com escolaridade equivalente, até o final do sexto ano de vigência deste PNE. Esta meta, embora restrita ao segmento docente, é de grande impacto e constitui-se em reivindicação histórica do campo, apresentando estratégias importantes na consecução de uma efetiva política de valorização do profissional do magistério ao articular salário, carreira e condições de trabalho.

A Meta 18, assegurar, no prazo de dois anos, a existência de planos de carreira para os/as profissionais da educação básica e superior pública de todos os sistemas de ensino e, para o plano de carreira dos/as profissionais da educação básica pública, tomar como referência o piso salarial nacional profissional, é fundamental para o setor, a despeito de negligenciar os profissionais do setor privado. Uma estratégia polêmica é a 18.3, realizar, por iniciativa do MEC, a cada dois anos a partir do segundo ano de vigência deste $\mathrm{PNE}$, prova nacional para subsidiar os estados, o DF e os municípios, mediante adesão, na realização de concursos públicos de admissão de profissionais do magistério da educação básica pública. Há vários questionamentos quanto ao estabelecimento de prova nacional envolvendo as questões sobre a autonomia dos entes subnacionais, bem como seus limites pedagógicos. A referida meta e suas estratégias secundarizam os direitos dos profissionais da educação que atuam no setor privado, sendo este um limite estrutural da meta, uma vez que a valorização dos profissionais independe do locus em que atuam. (DOURADO, 2016, p. 33).

Essas metas do PNE constituem importantes proposições, mas não garantem a sua materialidade, pois este processo será resultante das ações e políticas a serem efetivados pelos profissionais da educação e suas entidades representativas, conselhos, fóruns e outros atores coletivos junto à sociedade e ao executivo, ao legislativo, envolvendo, especialmente, os entes federados, seus órgãos executivos, normativos e de controle.

Após a aprovação do PNE e em sintonia com este plano, foram aprovados e homologados o Parecer CNE/CP nํ2, de 2015 que resultou na Resolução CNE/CP no 2, de 2015, do Conselho Nacional de Educação, que estabeleceu as Diretrizes Nacionais para a Formação Inicial e Continuada dos Profissionais do Magistério da Educação Básica; o Parecer CNE/CES no 264, de 2016 que resultou na Resolução CNE/CES noํ2, de 2016, do Conselho Nacional de Educação que estabeleceu as Diretrizes Nacionais para a Formação Inicial e Continuada dos Funcionários da Educação Básica. Mais recentemente, 
para atender a meta 15 do PNE, foi instituída da Política Nacional de Formação dos Profissionais da Educação Básica, por meio do Decreto nº 8.752, de 9 de maio de 2016.

O que configuram esses dispositivos e quais sinalizações políticas trazem para a formação inicial e continuada desses profissionais?

O Parecer CNE/CP nํㅡ 2, de 1015 que resultou na Resolução CNE/CP nํ2, de 2015, do Conselho Nacional de Educação, que estabeleceu as Diretrizes Nacionais para a Formação Inicial e Continuada dos Profissionais do Magistério da Educação Básica, definiu dinâmica formativa, tendo por eixo a base nacional comum, definida nos referidos marcos regulatórios, passando a requerer das instituições formadoras um projeto institucional de formação, que se articule ao Projeto de Desenvolvimento Institucional e Projeto Pedagógico Institucional, para que se materialize em projetos pedagógicos de cursos mais orgânicos e articulados à educação básica, e, desse modo, expressar a identidade institucional.

A esse respeito Dourado (2015, p. 307) afirma

[...] as novas DCNs enfatizam a necessária organicidade no processo formativo e sua institucionalização ao entender que o projeto de formação deve ser elaborado e desenvolvido por meio da articulação entre a instituição de educação superior e o sistema de ensino e instituições de educação básica, envolvendo a consolidação de Fóruns Estaduais e Distrital Permanentes de Apoio à Formação Docente, em regime de cooperação e colaboração. Tais questões implicam novos horizontes à dinâmica formativa dos profissionais do magistério da educação básica, pois a garantia do direito à educação a grupos e sujeitos historicamente marginalizados exige transformação na forma como as instituições de educação básica e superior estruturam seus espaços e tempos, suas regras e normas, incorporam novos materiais e recursos pedagógicos.

Para atender a essa concepção articulada de formação inicial e continuada, as novas DCNs definem que é fundamental que as instituições formadoras institucionalizem projeto de formação com identidade própria, em consonância com o Plano de Desenvolvimento Institucional (PDI), o Projeto Pedagógico Institucional (PPI) e o Projeto Pedagógico de Curso (PPC).

Considerando a importância da formação continuada oferecida pelos centros de formação de estados e municípios, bem como pelas instituições educativas de educação básica, as novas DCNs reconhecem esse lócus de formação continuada como parte constitutiva da nova política que se quer consolidar no país.

A partir dessa compreensão e tendo por eixo concepções norteadoras e a busca de sólida formação teórica e prática, a Resolução sinaliza três possibilidades para a formação inicial dos profissionais do magistério da educação básica: cursos de Licenciatura, cursos de Formação Pedagógica para Graduados e cursos de Segunda Licenciatura.

Em conformidade com a legislação vigente e com a efetiva atuação desses profissionais nos sistemas de ensino, a Resolução define que a formação inicial do profissional do magistério da educação básica, em nível superior, deve contemplar a formação para o exercício da docência e da gestão educacional e escolar na educação básica, adequada à 
área de conhecimento e às etapas e modalidades de atuação, garantindo acesso a conhecimentos específicos sobre gestão educacional e escolar, bem como formação pedagógica para o exercício da gestão e coordenação pedagógica e atividades afins, e que a formação inicial de profissionais do magistério será ofertada, preferencialmente, de forma presencial, com elevado padrão acadêmico, científico, tecnológico e cultural como definido na LDB.

O marco regulatório reafirma o respeito e valorização da diversidade como dinâmicas intrínsecas à formação dos profissionais da educação, bem como a necessária e fecunda articulação entre as instituições de educação superior, os sistemas de ensino, suas instituições e profissionais.

Na mesma direção situa-se Parecer CNE/CES nº 264, de 2016 que resultou na Resolução CNE/CES nํㅡ 2, de 2016, do Conselho Nacional de Educação, que estabeleceu as Diretrizes Nacionais para a Formação Inicial e Continuada dos Funcionários da Educação Básica e definiu a dinâmica formativa, tendo por eixo a base nacional comum definida nos referidos marcos regulatórios, passando a requerer das instituições formadoras projeto institucional de formação que se articule ao Projeto de Desenvolvimento Institucional e Projeto Pedagógico Institucional, materializando-se em projetos pedagógicos de cursos, mais orgânicos e articulados à educação básica, expressando, desse modo, sua identidade institucional.

Tendo eixos correlatos à formação inicial e continuada de profissionais do magistério sem, contudo, negligenciar a especificidade do trabalho pedagógico realizado pelos funcionários da educação básica, o Parecer CNE/CES nº 264, de 2016 e a Resolução CNE/ CES nํㅡㄹ de 2106 indicam que os cursos de formação inicial para os profissionais funcionários da educação básica, em nível superior, compreendem:

I. Curso Superior de Tecnologia em Educação e Processos de Trabalho: Secretaria Escolar;

II. Curso Superior de Tecnologia em Educação e Processos de Trabalho: Alimentação Escolar;

III. Curso Superior de Tecnologia em Educação e Processos de Trabalho: Infraestrutura Escolar;

IV. Curso Superior de Tecnologia em Educação e Processos de Trabalho: Multimeios Didáticos.

A Resolução estabelece, ainda, que é papel da instituição formadora definir, no seu projeto institucional, as formas de desenvolvimento da formação inicial, por meio de curso tecnológico para funcionários da educação básica, nas áreas mencionadas, 
articuladas às políticas de valorização desses profissionais e à base comum nacional explicitada na Resolução.

Outra determinação importante consiste na definição de que a instituição de ensino superior (IES), por meio de seu projeto institucional de formação, poderá estabelecer um eixo comum para os cursos superiores de Tecnologia em Educação e Processos de Trabalho, direcionado à formação de funcionários, desde que garantida a diversificação da formação em uma das áreas de formação previstas.

Após a aprovação dos Pareceres CNE/CP nํำ , de 2015 e CNE/CES nํ246, de 2016, por unanimidade pelo Conselho Nacional de Educação e homologados pelo Ministério da Educação, resultando nas Resoluções CNE/CP nº 2 , de 2015, que estabeleceu novas diretrizes curriculares nacionais (DCNs) para a formação inicial e continuada de profissionais do magistério da educação, e na Resolução CNE/CES no 2, de 2016, que estabeleceu novas diretrizes curriculares nacionais (DCNs) para a formação inicial e continuada de funcionários da educação, o Ministério da Educação submeteu documento preliminar de Política Nacional de Formação dos Profissionais da Educação Básica para consulta pública, em junho de 2015, e consolidou esta política por meio por meio do Decreto no 8.752, de 9 de maio de 2016.

Esta política nacional, em atendimento ao disposto na meta 15 do Plano Nacional de Educação, revoga os Decretos no⒍755, de 2009, e o Decreto nํㅜ 7.415, de 2010 e considera as proposições contidas nas novas diretrizes curriculares para a formação inicial de profissionais do magistério e de funcionários da educação básica, anteriormente discutidas.

Visando discutir o decreto que institui a Política Nacional de Formação dos Profissionais da Educação Básica proponho algumas questões para uma discussão inicial. Dentre estas, destaco as seguintes: o que propõe a referida política? Ela avança em direção à maior organicidade para a formação por meio de objetivos consistentes? Quais os limites que a política apresenta em relação aos decretos revogados?

Inicialmente é oportuno situar que a política nacional proposta busca atender a meta 15 do PNE - que estabeleceu o prazo de 2 anos para a instituição da política. No segundo momento, destacar que esta política busca articular em um mesmo decreto a formação para todos os profissionais da educação básica, o que pode se constituir em maior organicidade para a formação.

\section{O que propõe a nova política?}

No artigo 1 do Decreto fica explícito que a política nacional destina-se à formação para professores, pedagogos e funcionários, destacando que cabe ao Ministério da Educação, ao coordenar a Política Nacional de Formação, assegurar sua coerência com: 
I. as Diretrizes Nacionais do Conselho Nacional de Educação - CNE;

II. com a Base Nacional Comum Curricular;

III. com os processos de avaliação da educação básica e superior;

IV. com os programas e as ações supletivas do referido Ministério; e

V. com as iniciativas e os programas de formação implementados pelos estados, pelo Distrito Federal e pelos municípios.

O Decreto que institui a Política Nacional apresenta importantes e coerentes objetivos, face ao esforço do Estado Brasileiro no campo da formação inicial e continuada dos profissionais da educação básica, ao definir, no artigo 3ㅜㅡ os seguintes objetivos da Política Nacional de Formação dos Profissionais da Educação Básica:

I. instituir o Programa Nacional de Formação de Profissionais da Educação Básica, o qual deverá articular ações das instituições de ensino superior vinculadas aos sistemas federal, estaduais e distrital de educação, por meio da colaboração entre o Ministério da Educação, os Estados, o Distrito Federal e os Municípios;

II. induzir avanços na qualidade da educação básica e ampliar as oportunidades de formação dos profissionais para o atendimento das políticas deste nível educacional em todas as suas etapas e modalidades, e garantir a apropriação progressiva da cultura, dos valores e do conhecimento, com a aprendizagem adequada à etapa ou à modalidade cursada pelos estudantes;

III. identificar, com base em planejamento estratégico nacional, e suprir, em regime de colaboração, a necessidade das redes e dos sistemas de ensino por formação inicial e continuada dos profissionais da educação básica, de forma a assegurar a oferta em quantidade e nas localidades necessárias;

IV. promover a integração da educação básica com a formação inicial e continuada, consideradas as características culturais, sociais e regionais em cada unidade federativa;

V. apoiar a oferta e a expansão de cursos de formação inicial e continuada em exercício para profissionais da educação básica pelas instituições de ensino superior em diferentes redes e sistemas de ensino, conforme estabelecido pela Meta 15 do PNE;

VI. promover a formação de profissionais comprometidos com os valores de democracia, com a defesa dos direitos humanos, com a ética, com o respeito ao meio ambiente e com relações étnico-raciais baseadas no respeito mútuo, com vistas à construção de ambiente educativo inclusivo e cooperativo; 
VII. assegurar o domínio dos conhecimentos técnicos, científicos, pedagógicos e específicos pertinentes à área de atuação profissional, inclusive da gestão educacional e escolar, por meio da revisão periódica das diretrizes curriculares dos cursos de licenciatura, de forma a assegurar o foco no aprendizado do aluno;

VIII. assegurar que os cursos de licenciatura contemplem carga horária de formação geral, formação na área do saber e formação pedagógica específica, de forma a garantir o campo de prática inclusive por meio de residência pedagógica; e

IX. promover a atualização teórico-metodológica nos processos de formação dos profissionais da educação básica, inclusive no que se refere ao uso das tecnologias de comunicação e informação nos processos educativos.

O Decreto, em consonância aos decretos anteriores revogados, prevêno artigo $4^{\circ}$ que a Política Nacional de Formação de Profissionais da Educação Básica será orientada pelo Planejamento Estratégico Nacional, documento de referência, proposto pelo Ministério da Educação para a formulação de Planos Estratégicos em cada unidade federativa e para a implementação das ações e dos programas integrados e complementares. Tal sinalização é fundamental para a busca de maior organicidade das políticas e para o dimensionamento da formação necessária, a partir de diagnóstico pormenorizado e de proposiçãoo de planos estratégicos.

No artigo 5o, o Decreto define que a Política Nacional de Formação de Profissionais da Educação Básica contará com Comitê Gestor Nacional e com Fóruns Estaduais Permanentes de Apoio à Formação dos Profissionais da Educação Básica.

Em contraposição a essa importante conquista, em andamento em vários estados por meio de Fóruns estaduais atuantes e com significativa representatividade, o Decreto recua significativamente em relação aos decretos revogados, ao definir que o detalhamento da composição, das atribuições e formas de funcionamento do Comitê Gestor Nacional e dos Fóruns Estaduais Permanentes de Apoio à Formação dos Profissionais da Educação Básica será objeto de ato do Ministro de Estado da Educação, atendidas as disposições deste Decreto.

No parágrafo único do Artigo 6º há a definição de que o Comitê Gestor Nacional será presidido pelo Secretário-Executivo do Ministério da Educação e contará com a participação:

I. das secretarias e autarquias do Ministério da Educação;

II. de representantes dos sistemas federal, estaduais, municipais e distrital de educação;

III. de profissionais da educação básica, considerada a diversidade regional; e

IV. de entidades científicas. 
Da mesma forma, de maneira genérica, define-se no parágrafo único do Artigo 7. que, nos Fóruns Estaduais Permanentes e no Fórum Permanente do Distrito Federal, terão assento representantes da esfera federal, estadual, municipal, das instituições formadoras e dos profissionais da educação, visando à concretização do regime de colaboração.

Importante ressaltar, por outro lado, que a política nacional encontra-se em consonância com as diretrizes para a formação inicial e continuada de profissionais do magistério e de funcionários, anteriormente discutidas, ao definir no Art. 11. que, no âmbito dos planos estratégicos, o Ministério da Educação apoiará técnica ou financeiramente, conforme o caso:

I. cursos de formação inicial de nível superior em licenciatura;

II. cursos de formação inicial necessários para cada categoria dos profissionais da educação, decorrentes das demandas para as diferentes funções que desempenham;

III. cursos de segunda licenciatura, para profissionais do magistério em exercício, para que tenham formação na área em que atuam;

IV. cursos de formação pedagógica para graduados não licenciados;

V. cursos de formação técnica de nível médio e superior nas áreas de Secretaria Escolar, Alimentação Escolar, Infraestrutura Escolar, Multimeios Didáticos, Biblioteconomia e Orientação Comunitária, podendo este rol ser ampliado conforme a demanda observada e a capacidade da rede formadora;

VI. cursos de formação continuada;

VII. programas de iniciação à docência, inclusive por meio de residência pedagógica; e

VIII. ações de apoio a órgãos e instituições formadoras públicas vinculadas às Secretarias de Educação dos Estados, dos Municípios e do Distrito Federal.

Merece realce, nesta análise, o inciso VII que trata da iniciação a docência, inclusive por meio de residência pedagógica. É importante situar que a iniciação à docência tem sido objeto de grandes discussões e proposições no campo da formação de professores e, nas diretrizes nacionais para a formação inicial e continuada, podem ser contempladas a partir de projeto institucional de prática como componente curricular e de estágio supervisionado direcionado à educação básica. Outra importante experiência tem sido o Programa Institucional de Bolsas a Iniciação docente (Pibid), programa que concede bolsas a alunos de licenciatura participantes de projetos de iniciação à docência 
desenvolvidos por instituições de educação superior (IES) em parceria com instituições de educação básica da rede pública de ensino. Ao mesmo tempo, tramita no Congresso Nacional Projeto de Lei que visa instituir a Residência Docente, sem atentar para as diretrizes curriculares nacionais para a formação dos profissionais do magistério e que, a depender da concepção pedagógica, da carga horaria e das condições objetivas definidas, poderá ter significativo impacto na formação docente enfatizando apenas o "como fazer" e caminhando na contramão de uma política assentada em uma base nacional comum que garantiria sólida formação teórico-prática dos profissionais.

\section{Democracia e Estado de Direito: o PNE como epicentro}

Ao longo do texto sinalizamos para concepções em disputa em torno do que se entende por valorização dos profissionais da educação, e situamos o cenário em que eles se encontram no tocante à sua profissionalização e profissionalidade. Assumimos a concepção de valorização definida pela Conae 2014 cuja compreensão sinaliza para a relação entre formação inicial, formação continuada, carreira, salários e condições de trabalho, pois foi assim que se rompeu com a lógica de reduzir a valorização somente à formação dos profissionais.

Buscou-se, ainda, situar os profissionais do magistério e funcionários da educação como duas categorias em movimento, cujas histórias de lutas têm propiciado alguns avanços à valorização e consolidação de sua identidade, a despeito dos enormes desafios e assimetrias vivenciados nas condições objetivas de exercício profissional e profissionalidade.

Considerando o PNE, os pareceres e resoluções do Conselho Nacional de Educação, que resultaram, respectivamente, nas diretrizes curriculares nacionais para a formação inicial e continuada dos profissionais do magistério da educação Básica e dos funcionários da educação básica, e o Decreto n⿳ำ 8.752, de 9 de maio de 2016, que instituiu a Política Nacional de Formação dos Profissionais da Educação Básica, procedeu à análise dos referidos dispositivos legais, enfatizando a necessidade de maior organicidade às políticas de formação dos profissionais da educação básica.

As DCN para a formação inicial e continuada, discutidas ao longo do texto, avançam ao propor novos cenários formativos institucionalizados para esses profissionais, a partir de uma base comum nacional que, ao não se configurar como currículo mínimo, apresenta fundamentos essênciais à formação inicial e continuada, a serem objeto de institucionalização por parte das instituições de formação, em articulação com os sistemas de ensino, suas instituições e profissionais.

Por outro lado, o texto alerta para avanços e limites no Decreto nํㅗ.752, de 9 de maio de 2016, que instituiu a Política Nacional de Formação dos Profissionais da Educação 
Básica, o que vai requerer ação orgânica das entidades do campo e de seus profissionais, a fim de fortalecer as instâncias de deliberação previstas neste instrumento normativo, visando garantir ampla participação no diagnóstico, planejamento, proposição e materialização de políticas para a formação inicial, sem descurar dos enormos desafios postos à garantia de diretrizes nacionais de carreira, piso salarial nacional, condições de trabalho e saúde para os profissionais da educação que compõem, junto com a formação inicial e continuada, a concepção ampla de valorização profissional aprovada pela CONAE 2014.

Face ao cenário político atual do Estado Brasileiro, reafirma-se a luta pela retomada da democracia e do Estado de Direito em contraposição ao governo interino e às suas políticas de ajustes estruturais que afetam os diferentes setores, especialmente as políticas sociais. Tal cenário requer vigor no combate aos retrocessos que demarcam as políticas atuais, com especial relevo para a Proposta de Emenda à Constituição PEC 241/ 2016 que, ao prever que as despesas do governo federal por 20 anos, a partir de 2017, sejam corrigidas apenas pela inflação do ano anterior, vai comprometer sobretudo as áreas sociais, especialmente saúde e educação. No caso dessas áreas, poderá significar não apenas um recuo nos recursos, mas, de maneira estrutural, a quebra da vinculação constitucional de recursos duramente conquistada, além de invibializar o PNE.

Situa-se, ainda, a defesa da instituição do Sistema Nacional de Educação, configurado a partir de novos marcos na ação e na relação entre os entes federativos, sem descurar de normas e diretrizes nacionais, bem como da garantia constitucional na autonomia dos entes federados.

A instituição do SNE é fundamental para a efetivação das diretrizes, metas e estratégias do PNE, pois remete à efetiva institucionalização deste no bojo das relações federativas, o que envolve, em consonância ao arcabouço jurídico, maior organicidade na relação, na definição de responsabilidades e competências entre os entes federativos, contribuindo, desse modo, para avanços na agenda da política educacional por meio de efetiva coordenaçãoo federativa.

Recebido em maio de 2016 e aprovado em junho de 2016

\section{Notas}

1 O presente artigo recupera parte dos textos dos Pareceres CNE/CP nº 2, de 2015 e CNE/CES nº 246, de 2016, de minha relatoria.

2 Ver indicadores e desafios sobre os funcionários (DOURADO; MORAES, 2009).

3 A esse respeito ver Andrade e Santos (2009), Assis (2015), Melo (2009), Morais (2009), Prado, Oliveira e ChagaS (2009), entre outros. 
4 A respeito da área 21 ver Noronha (2009).

5 Profuncionário - Curso Técnico de Formação para os Funcionários da Educação que vem sendo efetivado, desde 2006, em regime de colaboração com os sistemas de ensino e com a participação de entidades como o Consed, a Undime, a Confederação Nacional dos Trabalhadores em Educação (CNTE) e os Conselhos Educação (CEE), e tendo como IES formadoras Universidades Públicas e, apartir de 2011, passam a contar com os Institutos Federais de Educação, Ciência e Tecnologia.

\section{Referências}

ANDRADE, G. C. O; SANTOS, J. B. Projeto Arara Azul: pioneiro na construção da identidade. Retratos da Escola, Brasília, CNTE, v. 3, n. 5, 2009. Disponível em: <http://www.esforce.org.br/index. php/semestral/article/view/35>. Acesso em: 13 jul. 2016.

ASSIS, Lúcia Maria de. Diagnóstico das iniciativas de formacão inicial, em nível superior, e formação continuada dos profissionais da Educação Básica (funcionário e técnico administrativo) efetivadas pelas IES, especialmente as Universidades Públicas e Institutos Federais. CNE/UNESCO, 2015. Disponível em: <http://portal.mec.gov.br/index.php?option=com_ docman\&view=download\&alias=26091-diagnostico-iniciativas-formacao-inicial-continuadaprofissionais-edfisica-basica-pdf\&Itemid=30192>. Acesso em: 13 jul. 2016.

BRASIL. Câmara dos Deputados. Proposta de Emenda à Constituição no 241/2016. Brasília: 2016. Disponível em: <www.camara.gov.br/proposicoesWeb/fichadetramitacao?idProposicao=2088351>. Acesso em: 13 jul. 2016.

Conselho Nacional de Educação. Câmara de Educação Básica. Resolução no 5, de 22 de novembro de 2005. Inclui, nos quadros anexos à Resolução CNE/CEB no 4, de 1999, de 8 de dezembro de 1999, como 21a Área Profissional,a área de Serviços de Apoio Escolar. Disponível em: <http://portal. mec.gov.br/cne/arquivos/pdf/rceb05_05.pdf>. Acesso em: 13 jul. 2016.

Câmara de Educação Básica. Resolução n⿳0 2, de 28 de maio de 2009. Diretrizes Nacionais para os Planos de Carreira e Remuneração dos Profissionais do Magistério da Educação Básica Pública. Disponível em: <http://portal.mec.gov.br/dmdocuments/resolucao_cne_ceb002_2009. pdf>. Acesso em: 13 jul. 2016.

Parecer n⿳0 2, de 9 de junho de 2015. Diretrizes Curriculares Nacionais para a formação inicial e continuada dos profissionais do magistério da educação básica. Disponível em: <http://portal. mec.gov.br/index.php?option=com_docman\&view=download\&alias=17625-parecer-cne-cp-2-2015aprovado-9-junho-2015\&category_slug=junho-2015-pdf\&Itemid=30192>. Acesso em: 13 jul. 2016.

Parecer n⿳0 246, de 4 de maio de 2016. Diretrizes Curriculares Nacionais para a formação inicial e continuada dos funcionários da educação básica. Disponível em: <http://portal.mec.gov.br/ index.php?option=com_docman\&view=download\&alias=40331-pces246-16-pdf\&category_slug=maio2016-pdf\&Itemid=30192>. Acesso em: 13 jul. 2016.

Resolução nº 2, de 13 de maio de 2016. Define as Diretrizes Curriculares Nacionais para a formação inicial e continuada em nível superior para funcionários da educação básica. Disponível em: <http://portal.mec.gov.br/index.php?option=com_docman\&view=download\&alias=41081-rces00216-pdf\&category_slug=maio-2016-pdf\&Itemid=30192>. Acesso em: 13 jul. 2016.

Resolução n⿳0 2, de $1^{0}$ de julho de 2015. Define as Diretrizes Curriculares Nacionais para a formação inicial em nível superior (cursos de licenciatura, cursos de formação pedagógica para graduados e cursos de segunda licenciatura) e para a formação continuada. Disponível em: <http:// 
portal.mec.gov.br/index.php?option=com_docman\&view=download\&alias=17719-res-cne-cp-00203072015\&category_slug=julho-2015-pdf\&Itemid=30192>. Acesso em: 13 jul. 2016.

. Constituição. Constituição da República Federativa do Brasil de 1988. Disponível em: <http:// www.planalto.gov.br/ccivil_03/constituicao/constituicaocompilado.htm>. Acesso em: 13 jul. 2016.

. Decreto $\mathbf{n}^{0}$ 8.752, de 9 de maio de 2016. Dispõe sobre a Política Nacional de Formação dos Profissionais da Educação Básica. Disponível em: <http://www.planalto.gov.br/ccivil_03/_Ato20152018/2016/Decreto/D8752.htm\#art19>. Acesso em: 13 jul. 2016.

. Decreto no 6.755, de 29 de janeiro de 2009. Institui a Política Nacional de Formação dos Profissionais do Magistério da Educação Básica, dispõe sobre o Programa de Formaçaoo Inicial em Serviço dos Profissionais da Educação Básica dos Sistemas de Ensino Público - Profuncionário, e dá outras providências. Disponível em: <www.capes.gov.br/images/stories/download/legislação/ Decreto-6755-2009.pdf>. Acesso em: 13 jul. 2016.

. Decreto $\mathbf{n}^{0}$ 7.415, de 30 de dezembro de 2010. Institui a Política Nacional de Formação dos Profissionais da Educação Básica, disciplina a atuação da Coordenação de Aperfeiçoamento de Pessoal de Nível Superior - CAPES no fomento de programas de formação inicial e continuada, e dá outras providências. Disponível em: <www.planalto.gov.br/ccivil_03/_Ato2007/2010/2010/Decreto/D7415.htm. >. Acesso em: 13 jul. 2016.

. Fórum Nacional de Educação. Documento Final da CONAE 2014. Brasília, 2014. Disponivel

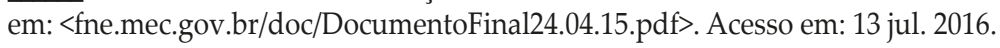

Lei $\mathbf{n}^{\mathbf{0}}$ 12.014, de 6 de agosto de 2009. Altera o art. 61 da Lei n. 9.394, de 20 de dezembro de 1996, com a finalidade de discriminar as categorias de trabalhadores que se devem considerar profissionais da educação. Disponível em: <http://www.planalto.gov.br/ccivil_03/_ato2007-2010/2009/ lei/112014.htm>. Acesso em: 08 jul. 2016.

. Lei no 11.738, de 16 de julho de 2008. Regulamenta a Alínea "e" do inciso III do caput do art. 60 do Ato das Disposições Transitórias, para Instituiu o Piso Salarial Profissional Nacional para os Profissionais do Magistério Público da Educação Básica.Disponível em: <www.planalto.gov.br/ ccivil_03/_ato2007-2010/2008/lei/111738.htm>. Acesso em: 13 jul. 2016.

. Lei no 9.394, de 20 de dezembro de 1996 .Diretrizes e Bases da Educação Nacional. Disponível em: <http://www.planalto.gov.br/ccivil_03/leis/L9394.htm>. Acesso em: 13 jul. 2016.

. Lei no 13.005, de 24 de junho de 2014. Aprova o Plano Nacional de Educação - PNE e dá outras providências. Disponível em: <www.planalto.gov.br/ccivil_03/_aato2011/2014/2014/lei/1130005.htm>. Acesso em: 13 jul. 2016.

DOURADO, Luiz Fernandes. Plano Nacional de Educação: política de Estado para a educação brasileira. Brasília: Inep, 2016. (Série Pne em Movimento, 1).

. Diretrizes curriculares nacionais para a formação inicial e continuada dos profissionais do magistério da educação básica: concepções e desafios. Educ. Soc., Campinas, v. 36, n. 131, p. 299-324, 2015. Disponível em: <http://www.scielo.br/scielo.php?script=sci_arttext\&pid=S010173302015000200299\&lng=pt\&nrm=iso >. Acesso em: 13 jul. 2016.

- MORAES, K. N. Funcionário de escola: indicadores e desafios. Retratos da Escola, Brasília, CNTE, v. 3, n. 5, 2009. Disponível em: <http://www.esforce.org.br/index.php/semestral/article/ view/33>. Acesso em: 13 jul. 2016.

LEÃO, Roberto Franklin; CLEIDE, Fátima; FERNANDES, Francisco das Chagas. Organização e valorização dos funcionários: cenário atual e desafios. Retratos da Escola, Brasília, CNTE, v. 3, n. 
5, 2009. Entrevista. Disponível em: <http://www.esforce.org.br/index.php/semestral/issue/view/7>. Acesso em: 13 jul. 2016.

MELO, M. T. L. O chão da escola: construção e afirmação da identidade. Retratos da Escola, Brasília, CNTE, v. 3, n. 5, 2009. Disponível em: <http://www.esforce.org.br/index.php/semestral/article/ view/31>. Acesso em: 13 jul. 2016.

MORAIS, José Valdivino. A carreira e a gestão da escola: valorização e democracia. Retratos da Escola, Brasília, CNTE, v. 3, n. 5, 2009. Disponível em: <http://www.esforce.org.br/index.php/semestral/article/ view/32>. Acesso em: 13 jul. 2016.

MONLEVADE, João A. C. História e construção da identidade: compromissos e expectativas. Retratos da Escola, Brasília, CNTE, v. 3, n. 5, 2009. Disponível em: <http://www.esforce.org.br/index.php/ semestral/article/view/27>. Acesso em: 13 jul. 2016.

NORONHA, Maria Izabel A. Diretrizes de Carreira e Área 21: história e perspectivas. Retratos da Escola, Brasília, CNTE, v. 3, n. 5, 2009. Disponível em: <http://www.esforce.org.br/index.php/ semestral/article/view/29>. Acesso em: 13 jul. 2016.

PRADO, J. C. B.; OLIVEIRA, J. A.; CHAGAS, M. Defe, 15 anos de luta e história: o que seria da educação sem ele? Retratos da Escola, Brasília, CNTE, v. 3, n. 5, 2009. Disponível em: <http://www. esforce.org.br/index.php/semestral/article/view/28>. Acesso em: 13 jul. 2016.

VIEIRA, Juçara Dutra. Funcionário da educação: o caso do Brasil é singular? Retratos da Escola, Brasília, CNTE, v. 3, n. 5, 2009. Disponível em: <http://www.esforce.org.br/index.php/semestral/article/ view/26. >. Acesso em: 13 jul. 2016. 


\title{
The enhancement of education professionals Challenges to ensuring democratic achievements
}

\begin{abstract}
This article has as its main theme the national conferences, the PNE* and the proposals and opinions of my own authorship of the $\mathrm{CNE} / \mathrm{CP}^{* *}$, having been accepted unanimously by the National Education Council and approved by the $\mathrm{MEC}^{* * *}$, resulting in resolutions such as the National Guidelines for Initial and Continuous Training for Magisterium Professionals and the National Curriculum Guidelines for Initial and Continuous Training for Education officials, together with the decree establishing the National Policy on Education for Basic Education Professionals This is currently being threatened at the current time, despite it having being achieved in recent years.
\end{abstract}

Keywords: Educational policies. PNE. Enhancment. Formation. Education professionals.

* National Education Plan

** National Education Council / Full Council

${ }^{* * *}$ Ministry of Education

\section{Valorisation des professionnels de l'éducation Défis pour garantir les conquêtes de la démocratie}

RÉSUMÉ: L'article a pour axe principal les conférences nationales, le $\mathrm{PNE}^{*}$ et les propositions miennes des rapports $\mathrm{CNE} / \mathrm{CP}^{* *}$ approuvés à l'unanimité par le Conseil National de l'Education et homologués par le $\mathrm{MEC}^{* * *}$, lesquels ont donné lieu à des résolutions, comme les Directives Nationales de Programme pour la Formation Initiale et Continue des Professionnels de l'Enseignement, les Directives Nationales de Programme pour la Formation Initiale et Continue des Fonctionnaires de l'Education ainsi qu'au Décret qui a établi la Politique Nationale de Formation des Professionnels de l'Education Basique, aujourd'hui menacés, et ce en dépit des conquêtes des dernières années.

Mots-clés: Politiques éducatives. PNE. Valorisation. Formation. Profissionnels de leéducation.

* Plan National d'Education

** Conseil National d'Education / Conseil plénier

*** Ministére de l'Education

\section{Valoración de los profesionales de la educación Desafíos para garantizar conquistas de la democracia}

RESUMEN: El eje del artículo son las conferencias nacionales, el PNE* y las proposiciones de informes del CNE/CP** de mí autoría, aprobados por unanimidad por el Consejo Nacional de Educación y homologados por el $\mathrm{MEC}^{* * *}$, resultando en resoluciones, como las Directrices Curriculares Nacionales para la Formación Inicial y Continua de Profesionales del Magisterio y las Directrices Curriculares Nacionales para la Formación Inicial y Continua de Empleados de la Educación, y en el Decreto que ha instituido la Política Nacional de Formación de los Profesionales de la Educación Básica, hoy amenazados, pese a las conquistas de los últimos años.

Palabras clave: Políticas educativas. PNE. Valoración. Formación. Profesionales de la educación.

* Plan Nacional de Educación

** Consejo Nacional de Educación / Consejo Pleno

*** Ministerio de la Educación 